\title{
REGIONALIZAÇÃO DOS SERVIÇOS DE SANEAMENTO NA REGIÃO NORDESTE
}

\section{REGIONALIZATION OF SANITATION SERVICES IN THE NORTHEAST REGION}

\author{
José Irivaldo Alves Oliveira Silva ${ }^{(1)}$ \\ Professor da Universidade Federal de Campina Grande. Doutor em Direitos Humanos Ciências Sociais. Professor no \\ Programa de Pós-Graduação em Ciências Jurídicas, no mestrado em Gestão e Regulação de Recursos Hídricos, no \\ Programa de Pós-Graduação em Desenvolvimento Regional e no Programa de Pós-Graduação em Administração. \\ Suely Gonçalves da Conceição ${ }^{(2)}$ \\ Pós-Graduanda em Planejamento Urbano pela UNDB. São Luís - MA e servidora da Companhia de água e esgoto do \\ Estado.
}

E-mail ${ }^{(1)}$ : irivaldo.cdsa@gmail.com

\section{RESUMO}

A questão a ser abordada no presente trabalho é qual o desenho geral da regionalização do saneamento no nordeste à luz do novo marco? O objetivo foi apresentar uma análise inicial acerca dos modelos já aprovados no nordeste brasileiro. Como metodologia utilizamos como instrumentos a pesquisa documental e bibliográfica, e método o indutivo. Ainda há muitas incertezas sobre se esses modelos resultarão na universalização efetivamente das áreas mais vulneráveis do nordeste, que são muitas no semiárido. Portanto, os efeitos da regionalização ainda são desconhecidos, porém seu início não foi em consonância com um projeto dialogado e, por conseguinte, participativo.

\begin{abstract}
The question to be addressed in this work is what is the general design of the regionalization of sanitation in the Northeast in light of the new framework? The objective was to present an initial analysis of the models already approved in the Brazilian northeast. As a methodology, we use documental and bibliographical research as instruments, and the inductive method. There are still many uncertainties about whether these models will result in the effective universalization of the most vulnerable areas in the northeast, which are many in the semiarid region. Therefore, the effects of regionalization are still unknown, but its beginning was not in line with a dialogued and, therefore, participatory project.
\end{abstract}

Palavras-chave: Saneamento. Regionalização. Água. Universalização.

Key words: Sanitation. Regionalization. Water. Universalization.

\section{INTRODUÇÃO}

Assegurar o Direito Humano à Água e Saneamento - DHAS, no sistema de saneamento, passa por travar a disputa que ocorre na implementação da Lei $\mathrm{N}^{\circ}$ 14.026, de 15 de julho de 2020, notadamente na dimensão atribuída à regionalização. Adotar a prestação de serviços regionalizada, pode implicar no desmonte do sistema atual, onde os operadores são majoritariamente as empresas públicas, e em que pese algumas dificuldades, mas tem assegurado a implantação e operação de serviços de águas e esgotos na maioria dos municípios brasileiros. Sendo assim, considerando esse momento inicial do processo de implementação da lei, a proposta do trabalho é apresentar uma análise inicial acerca dos modelos já aprovados no nordeste brasileiro. Isso se torna importante no presente momento, pois ainda os efeitos dessa nova lei são incertos, principalmente para a maior parcela de municípios pequenos do Brasil que possuem baixas condições de saneamento.Pretende-se apresentar 
os principais aspectos que envolvem a implementação da regionalização no nordeste. A metodologia adotada foi dedutiva, baseada na análise documental e a pesquisa bibliográfica.

\section{CRISE HÍDRICO-SANITÁRIA NO NORDESTE}

O nordeste tem problemas de disponibilidade hídrica no território do semiárido. Sendo que $88 \%$ da zona urbana está atendida por rede de abastecimento, segundo dados do Sistema Nacional de Informações sobre Saneamento (SNIS, 2020). Entretanto, apenas 28,3\% do esgoto gerado é coletado, sendo que apenas $33,7 \%$ desse total de resíduos é efetivamente tratado. O relatório de 2019, publicado em 2020, indica também que dos $28,3 \%$ de esgoto coletado tem-se $82,7 \%$ de tratamento. Isso revela um panorama bem trágico para o nordeste, uma vez que nem o pouco esgoto coletado tem seu tratamento na totalidade.

\section{NOVO MARCO DO SANEAMENTO BÁSICO}

Em 20 de julho de 2020 foi publicada a lei n. 14.026, conhecida como o "novo marco do saneamento". Esse marco provocou uma série de modificações legislativas não só na lei 11.445, mas em outros diplomas legais. Dentre as leis que foram modificadas, podem ser citadas:

1) A lei que instituiu a Agência Nacional de Águas (Lei $n^{\circ} 9.984 / 2000$ );

2) O Estatuto da Metrópole (Lei $\left.n^{\circ} 13.089 / 2015\right)$;

3) A lei sobre contratos de programa (Lei $\left.{ }^{\circ} 11.107 / 2005\right)$;

4) A lei da Política Nacional de Resíduos Sólidos (Lei no 12.305/2010)

Porém, considerando o objeto do presente ensaio, é possível indicar que a maior promessa desse marco do saneamento é a universalização através da implementação de modelos de regionalização que promovam esse desejo. Portanto, a regionalização é indicada como meio para o acesso pleno de todos ao saneamento. Essa é uma premissa basilar da nova lei. No art. $4^{\circ} \mathrm{A}$ da referida lei, $\S 3^{\circ}$, inciso $\mathrm{V}$, tem-se o seguinte: “(...) incentivar a regionalização da prestação dos serviços, de modo a contribuir para a viabilidade técnica e econômico-financeira, a criação de ganhos de escala e de eficiência e a universalização dos serviços; $(\ldots)$ "

Dessa forma, a regionalização é a aposta para ganhos de escala, eficiência da universalização dos serviços, sendo essencial, segundo o legislador, para a viabilidade técnica e econômicofinanceira. O art. 49, da mesma lei, também reafirma como objetivo da Política Federal de Saneamento Básico, a regionalização.

A prestação regionalizada é definida no art. $3^{\circ}$, inciso VI, da lei como sendo: "modalidade de prestação integrada de um ou mais componentes dos serviços públicos de saneamento básico em determinada região cujo território abranja mais de um Município, podendo ser estruturada em: (...)". Assim estabelece o seguinte modelo: a) região metropolitana, aglomeração urbana ou microrregião: (...) b) unidade regional de saneamento básico: (...) c) bloco de referência: (...).

Com isso, fica extinta a possibilidade de celebração dos contratos de programa e de aplicação do subsídio cruzado, o que possibilitava a prestação desses serviços públicos em municípios muito pequenos, cuja operação não seria viável de outro modo. Isso, certamente, poderá impactar diretamente no perfil dos prestadores desses serviços, mudando o quadro que está demonstrado no gráfico 1. Além disso, foi dado o prazo de 1 ano para os estados aprovarem suas leis de regionalização criando os modelos específicos.

Há de se considerar que a regionalização irá trazer alterações nas áreas que afetam o financiamento, o controle social, as modalidades de prestação de serviços, a regulação, o planejamento, principalmente quando se trata do ente público como operador do sistema. A Lei 14.026, dificulta o acesso a fundos públicos, desconsidera a Constituição Federal de 1988 em relação 
a autonomia dos entes federativos e instrumentos de coordenação federativo como o Estatuto das Metrópoles.

\section{A DINÂMICA DA REGIONALIZAÇÃO ATUALMENTE}

O prazo para que os estados formatassem os seus modelos de regionalização através das leis estaduais finalizou em 15 de julho de 2021. Desse modo, ainda existem 9 estados que estão com pendências na aprovação dos seus projetos de lei. Atualmente, conta-se com 17 modelos de regionalização aprovados em lei. As únicas regiões que tiveram leis aprovadas em todos os estados foram a sul e a nordeste. Norte, Centro-Oeste e Sudeste ainda precisam completar esse processo. O quadro 1 ilustra a situação específica do nordeste.

Quadro 1 - Leis de regionalização aprovadas no nordeste

\section{SITUAÇÃO DA REGIONALIZAÇÃo NA REGIÃO NORDESTE}

\begin{tabular}{|c|c|c|c|c|}
\hline ESTADO & $\begin{array}{c}\text { Leis } \\
\text { aprovadas }\end{array}$ & Principais características & Capital & Companhia Estadual \\
\hline PB & $\begin{array}{l}\text { LC n. } \\
168 / 2021\end{array}$ & $\begin{array}{l}4 \text { microrregiões. O modelo de } \\
\text { regionalização foi baseado em } \\
\text { critério sócio-econômicos, } \\
\text { estabelecendo uma governança } \\
\text { autônoma para cada uma das } 4 \\
\text { microrregiões. }\end{array}$ & $\begin{array}{l}\text { integra uma das } \\
\text { microrregiões }\end{array}$ & $\begin{array}{l}\text { A lei permite a criação de } \\
\text { subsidiárias da Companhia } \\
\text { Estadual; a modificação da } \\
\text { natureza das ações; alienar, de } \\
\text { forma gratuita ou onerosa, as } \\
\text { ações. }\end{array}$ \\
\hline PE & $\begin{array}{l}\text { LC n. } \\
455 / 2021\end{array}$ & $\begin{array}{l}2 \text { microrregiões de saneamento. } \\
\text { A estrutura de governança é } \\
\text { muito semelhante a da Paraíba, } \\
\text { conferindo autonomia às } \\
\text { microrregiões e instituindo } \\
\text { colegiados. }\end{array}$ & $\begin{array}{l}\text { integra uma das } 2 \\
\text { microrregiões } \\
\text { criadas }\end{array}$ & Não menciona \\
\hline $\mathrm{RN}$ & $\begin{array}{l}\text { LC n. } \\
682 / 2021\end{array}$ & $\begin{array}{l}2 \text { microrregiões. Instituiu um } \\
\text { modelo de governança pautado } \\
\text { em autarquias } \\
\text { intergovernamentais. Segundo o } \\
\text { governo, pautou-se na divisão } \\
\text { em bacias hidrográficas e dados } \\
\text { sócio econômicos, considerando } \\
\text { que boa parte dos municípios } \\
\text { estão inseridos no semiárido. }\end{array}$ & $\begin{array}{l}\text { integra uma das } \\
\text { microrregiões }\end{array}$ & Não menciona \\
\hline $\mathrm{CE}$ & $\begin{array}{l}\text { LC n. } \\
247 / 2021\end{array}$ & $\begin{array}{l}3 \text { microrregiões. A estrutura das } \\
\text { microrregiões levou } \\
\text { consideração a delimitação das } \\
\text { bacias hidrográficas, a divisão } \\
\text { da infraestrutura operacional dos } \\
\text { serviços de saneamento básico e } \\
\text { as particularidades sociais, } \\
\text { econômicas e políticas dos } \\
\text { territórios envolvidos. Cada } \\
\text { microrregião será responsável } \\
\text { pelo planejamento, regulação, } \\
\text { fiscalização e prestação, direta } \\
\text { ou indireta, dos serviços } \\
\text { públicos de abastecimento de } \\
\text { água, esgotamento sanitário e } \\
\text { manejo de águas pluviais } \\
\text { urbanas. }\end{array}$ & $\begin{array}{l}\text { integra uma das } \\
\text { microrregiões }\end{array}$ & Não menciona. \\
\hline
\end{tabular}




\section{SITUAÇÃO DA REGIONALIZAÇÃO NA REGIÃO NORDESTE}

\begin{tabular}{|c|c|c|c|c|}
\hline PI & $\begin{array}{l}\text { LC n. } \\
257 / 2021\end{array}$ & $\begin{array}{l}11 \text { microrregiões. Também } \\
\text { adota o formato autárquica das } \\
\text { microrregiões. Trata-se de uma } \\
\text { lei que alterou outra lei, a da } \\
\text { Política de Saneamento do Piauí. }\end{array}$ & $\begin{array}{l}\text { integra uma das } \\
\text { microrregiões }\end{array}$ & Não menciona \\
\hline SE & $\begin{array}{l}\text { LC n. } \\
176 / 2009\end{array}$ & $\begin{array}{l}13 \text { microrregiões. Lei aprovada } \\
\text { anteriormente ao marco } \\
\text { regulatório e que passa por } \\
\text { avaliação de comissão para } \\
\text { possível adequação, no que for } \\
\text { necessário, ao novo marco } \\
\text { regulatório federal. }\end{array}$ & $\begin{array}{l}\text { é uma das } \\
\text { microrregiões }\end{array}$ & $\begin{array}{l}\text { Protegida, sob anuência dos } \\
\text { colegiados das microrregiões, } \\
\text { porém a lei está sendo adequada } \\
\text { ao novo marco. }\end{array}$ \\
\hline AL & $\begin{array}{l}\text { Lei n. } \\
8.358 / 2020\end{array}$ & $\begin{array}{l}2 \text { Unidades Regionais de } \\
\text { Saneamento Básico mais a } \\
\text { região metropolitana de Maceió. } \\
\text { Adotou o modelo de gestão } \\
\text { associada interfederativa, não } \\
\text { indicando se será por meio de } \\
\text { autarquias. O Governo agora } \\
\text { está chamando os municípios a } \\
\text { aderirem aos blocos aprovados } \\
\text { na lei estadual. }\end{array}$ & $\begin{array}{l}\text { Separada na } \\
\text { região } \\
\text { metropolitana }\end{array}$ & Não protegida \\
\hline BA & $\begin{array}{l}\text { LC n. } \\
48 / 2019\end{array}$ & $\begin{array}{l}19 \text { microrregiões, sendo que } \\
\text { Salvador não está incluída nessa } \\
\text { divisão. Integrou uma lógica a } \\
\text { partir da unidade r de } \\
\text { planejamento da bacia } \\
\text { hidrográfica. Também adotou o } \\
\text { modelo de autarquia } \\
\text { microrregional. }\end{array}$ & Separada & Não menciona \\
\hline MA & 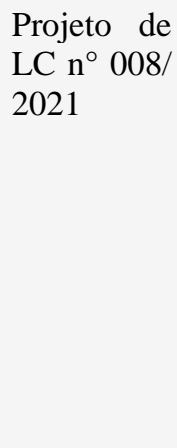 & 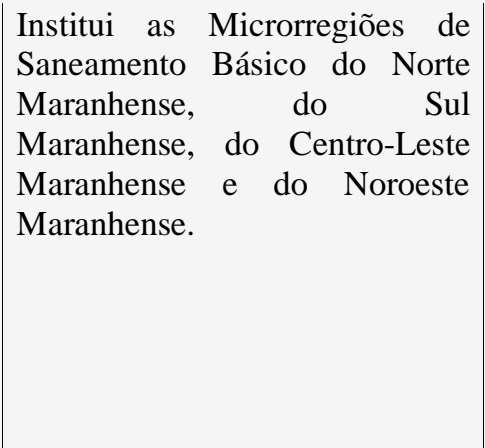 & $\begin{array}{l}\text { integra uma das } \\
\text { microrregiões }\end{array}$ & $\begin{array}{l}\text { Fica o Poder Executivo } \\
\text { autorizado a: } \\
\text { I - criar subsidiárias da } \\
\text { Companhia de Saneamento } \\
\text { Ambiental do Maranhão } \\
\text { CAEMA, Sociedades de } \\
\text { Propósito Específico - SPE ou } \\
\text { outras sociedades empresárias, } \\
\text { com atuação em uma ou mais das } \\
\text { microrregiões instituídas por esta } \\
\text { Lei Complementar; }\end{array}$ \\
\hline
\end{tabular}

Fonte: os autores

Os estados formalizaram suas leis de regionalização do saneamento para o cumprimento da exigência legal existente na lei federal. Entretanto, ainda é incerto o sucesso desse processo quando se parte para pensar no modelo em si.

A maior parte das leis aprovadas no nordeste são referentes ao novo marco do saneamento aprovado em 2020 pelo Congresso Nacional, à exceção de Sergipe, Piauí e Bahia, que já possuíam diplomas legais que estabeleciam uma regionalização do saneamento em seus territórios, porém o Piauí alterou a lei anterior. 

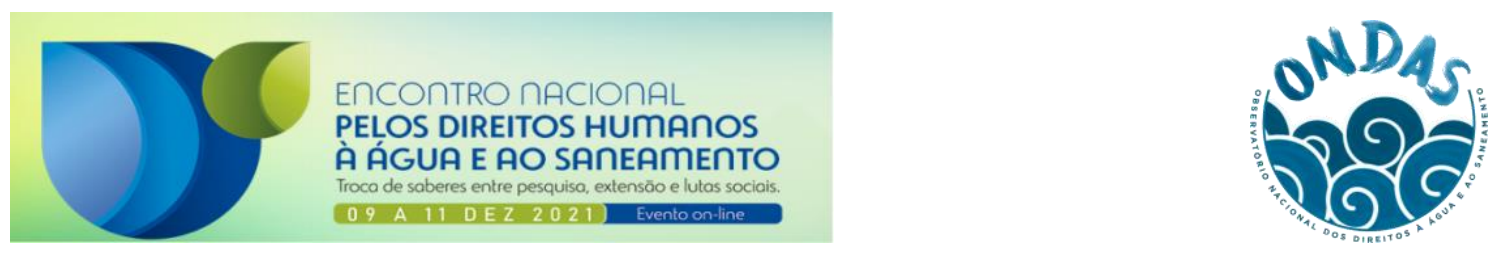

É interessante destacar a lei complementar sergipana citada no quadro 2, que cria 13 microrregiões, não estabelece a forma de governança, porém, delega à companhia estadual de saneamento a administração das regionais criadas. Isso, atualmente, vai de encontro à lei federal que estabelece justamente o contrário, mantendo os contratos vigentes e estabelecendo a obrigatoriedade de licitação para os novos contratos a serem estabelecidos.

O Estado de Alagoas optou pelo modelo de Unidade Regional de Saneamento Básico (URSB) que possibilita agrupar municípios não necessariamente limítrofes, deixando de fora a região metropolitana de Alagoas que, inclusive, já se submeteu ao leilão, que incluiu 13 municípios, que compõem a região metropolitana de Maceió.

Dessa forma, os modelos de regionalização no nordeste centralizaram-se essencialmente nas microrregiões, formada por autarquias de natureza especial, e com adesão, ao que parece, obrigatória dos municípios inseridos nas respectivas divisões regionais, à exceção de Alagoas. Até o presente momento o estado que se encontra no estágio mais avançado do processo de abertura do setor de saneamento à iniciativa privada é Alagoas. Depois tem-se o Piauí em que o governo menciona abertamente a possibilidade de passar o controle do saneamento à iniciativa privada. A pergunta que fica no ar é se esses modelos serão suficientes para universalizar o saneamento, incluindo cidades e campo em um mesmo esforço, ou teríamos esforços diferenciados mais focados no primeiro. Isso fica mais complexo em contextos de abertura para a iniciativa privada que tem interesse nas melhores "fatias" desse "bolo".

\section{CONCLUSÃO}

Os resultados dessa regionalização ainda não são conhecidos, estão em curso esses projetos. Porém, o que se pode antever são projetos pouco dialogados com a população, feitos de forma rápida para o cumprimento do prazo legal da lei federal. Portanto, trata-se de um fenômeno cujos efeitos com foco na universalização dos serviços de água e esgotamento sanitário ainda serão conhecidos. Um elemento é possível adiantar, ainda há um processo de invisibilização do saneamento rural. O prenúncio que se tem até agora é o preparo para uma privatização seletiva dos serviços, separandose regiões rentáveis de regiões deficitárias. É preciso monitorar e acompanhar de perto esses processos acontecendo a partir de agora.

\section{REFERÊNCIAS}

ALBUQUERQUE, Catarina de. Manual prático para a realização dos direitos humanos à água e ao saneamento, Vol 1. Introdução. Relatora Especial da ONU. Disponível em https://www.ohchr.org/Documents/Issues/Water/Handbook/Book1_intro_pt.pdf Acesso em: 12 de Maio de 2021.

GOVERNO DO BRASIL. Lei 14.445, de 05 de janeiro de 2007. Disponível em $<$ https://legislacao.presidencia.gov.br/atos/?tipo=LEI\&numero=11445\&ano=2007\&ato=9bacXWU 90MRpWTad7> Acesso em: 28 de junho de 2020.

Lei 14.026, de 15 de julho de 2020. Disponível em < https://legislacao.presidencia.gov.br/atos/?tipo=LEI\&numero=14026\&ano=2020\&ato=cfaATWE9 EMZpWT417> Acesso em: 21 de julho de 2020.

GOVERNO DO ESTADO DE ALAGOAS. Lei 8358/2020 de 03 de dezembro de 2020. Disponível em < https://leisestaduais.com.br/al/lei-ordinaria-n-8358-2020-alagoas-institui-as-unidades- 
regionais-de-saneamento-basico-no-estado-de-alagoas-e-d\%E2\%80\%A6 > Acesso em: 12 de agosto de 2021

ALAGOAS. Decreto $\mathbf{N}^{\mathbf{7}} \mathbf{7 4 . 2 6 1}$, de 7 de maio de 2021. Disponível em < https://www.imprensaoficial.al.gov.br/storage/files/diary/2021/05/DOEAL-2021-05-10SUPLEMENTO-SPaKQTIjLOxLQQHeU2gfAusGqjyd4ScVAGvVatMyRzTHe5SgrAmAe.pdf > Acesso em: 12 de agosto de 2021

DA BAHIA. Lei Complementar $\mathbf{N}^{\circ} 48$ de 10 de junho de 2019. Disponível em <http://www.sihs.ba.gov.br/arquivos/File/PLC_48_Microrregioes.pdf $>$ Acesso em: 12 de agosto de 2021

Decreto $\mathrm{N}^{\circ} 19.337$ de 14 de novembro de 2019. Disponível em < http://www.sihs.ba.gov.br/arquivos/File/Decreto Microrregioes.pdf > Acesso em: 12 de agosto de 2021

DO CEARÁ. Lei Complementar 247/2021 de 18 de junho de 2021. Disponível em < https://www.legisweb.com.br/legislacao/?id=416053 $>$ Acesso em: 12 de agosto de 2021

DO MARANHÃO. Projeto de Lei Complementar 008/2021 de 26 de agosto 2021. Disponível em < https://www.al.ma.leg.br/diarios/arquivos/DIARIO 238 01.09.2021 .pdf>. Pagina 4. Acesso em: 01 de setembro de 2021.

DA PARAÍBA. Lei Complementar No 168, de 22 de junho de 2021.

Disponível em < http://www.diariooficial.rn.gov.br/> Acesso em: 12 de agosto de 2021.

DE PERNAMBUCO. Lei Complementar 455/2021 de 13 de julho de 2021. Disponível em $<$ http://legis.alepe.pe.gov.br/texto.aspx?id=56009\&tipo $>$ Acesso em: 13 de agosto de 2021

DO PIAUÍ. Lei Complementar 257/2021 de 16 de julho de 2021. Disponível em <https://www.pi.gov.br/wp-content/uploads/2021/07/DIARIO16 80a0354471 210716213529 p\%C3\%A1ginas-1-3 210716 214007-1.pdf > Acesso em: 13 de agosto de 2021

DO RIO GRANDE DO NORTE. Lei Complementar $\mathbf{N}^{\mathbf{6}}$ 682, de 15 de julho de 2021. Disponível em < http://www.diariooficial.rn.gov.br/> Acesso em: 13 de agosto de 2021.

DE SERGIPE. Lei Complementar $\mathbf{N}^{\circ} 176$ de 18 de dezembro de 2009. Disponível em <http://177.47.183.3/sapl/sapl_documentos/norma_juridica/8464_texto_integral > Acesso em: 13 de agosto de 2021.

INSTITUTO BRASILEIRO DE GEOGRAFIA E ESTATÍSTICA (IBGE). Cidades e Estados.

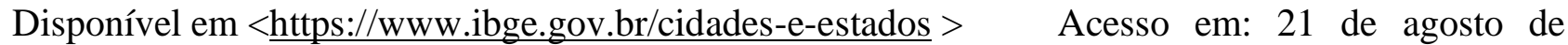
2021.

INSTITUTO BRASILEIRO DE GEOGRAFIA E ESTATÍSTICA (IBGE). PNSB - Pesquisa Nacional de Saneamento Básico, 2008. Rio de Janeiro: IBGE, 2010.

SISTEMA NACIONAL DE INFORMAÇÃO EM SANEAMENTO BÁSICO (SNIS). Diagnóstico dos serviços de água e esgoto. Brasília: MDR, 2020. 